\title{
Vapor Compression and Thermoelectric Heat Pumps for a Cascade Distillation Subsystem: Design and Experiment
}

\author{
Lisa R. Erickson* and Eugene K. Ungar ${ }^{\dagger}$ \\ NASA/Johnson Space Center, Houston, TX, 77058
}

\begin{abstract}
Humans on a spacecraft require significant amounts of water for drinking, food, hydration, and hygiene. Maximizing the reuse of wastewater while minimizing the use of consumables is critical for long duration space exploration. One of the more promising consumable-free methods of reclaiming wastewater is the distillation/condensation process used in the Cascade Distillation Subsystem (CDS). The CDS heats wastewater to the point of vaporization then condenses and cools the resulting water vapor.

The CDS wastewater flow requires heating for evaporation and the product water flow requires cooling for condensation. Performing the heating and cooling processes separately would require two separate units, each of which would demand large amounts of electrical power. Mass, volume, and power efficiencies can be obtained by heating the wastewater and cooling the condensate in a single heat pump unit.

The present work describes and compares two competing heat pump methodologies that meet the needs of the CDS: 1) a series of mini compressor vapor compression cycles and 2) a thermoelectric heat exchanger. In the paper, the CDS system level requirements are outlined, the designs of the two heat pumps are described in detail, and the results of heat pump analysis and performance tests are provided. The mass, volume, and power requirement for each heat pump option is compared and the advantages and disadvantages of each system are listed.
\end{abstract}

\section{Nomenclature}

$\mathrm{COP}=$ coefficient of performance

$Q_{\text {cooling }}=$ cooling provided by heat pump

$Q_{\text {heating }}=$ heating provided by heat pump

$T_{\text {cold }}=$ cold side (condensate) process fluid temperature

$T_{\text {cond }} \quad=$ heat pump refrigerant condensing (hot side) temperature

$T_{\text {evap }}=$ heat pump refrigerant evaporating (cold side) temperature

$T_{\text {hot }}=$ hot side (wastewater) process fluid temperature

UA $=$ overall heat exchanger heat transfer coefficient

\section{Introduction}

L ong duration space exploration will require that water be recycled to the maximum extent possible while using the minimum quantity of consumables. A promising consumable-free wastewater recycling technology is the Cascade Distillation Subsystem (CDS). In the CDS, the wastewater flows through a concentrating recirculating loop where it is mostly vaporized. The resulting steam is condensed within the CDS and is removed for final purification. The CDS is designed to recover more than $90 \%$ of the water from the incoming wastewater stream.

Performing the CDS heating and cooling processes separately would require two separate units, each of which would use a great deal of electrical power. Power, mass, and volume efficiencies can be obtained by heating the wastewater and cooling the condensate in a single heat pump unit. Prior CDS work has used a thermoelectric heat

\footnotetext{
* Aerospace Technologist, Design \& Analysis Branch, EC2, 2101 NASA Parkway, Houston TX 77058.

${ }^{\dagger}$ Senior Thermal and Fluid Analyst, Design \& Analysis Branch, EC2, 2101 NASA Parkway, Houston TX 77058.
} 
pump (TEHP) for the heating/cooling function. The TEHP used previously was built solely for ground testing and is not suitable for flight. To take the next step in CDS development, design and testing of a flight-like heat pump is required.

In the decade since the start of the CDS development, thermoelectric technology has improved and small vapor compression heat pumps have become available. This has opened up two options to perform the heat pump function: an improved TEHP and a vapor compression system.

The present work describes and compares the two competing heat pump methodologies for the CDS: a prototypic TEHP and a triplex vapor

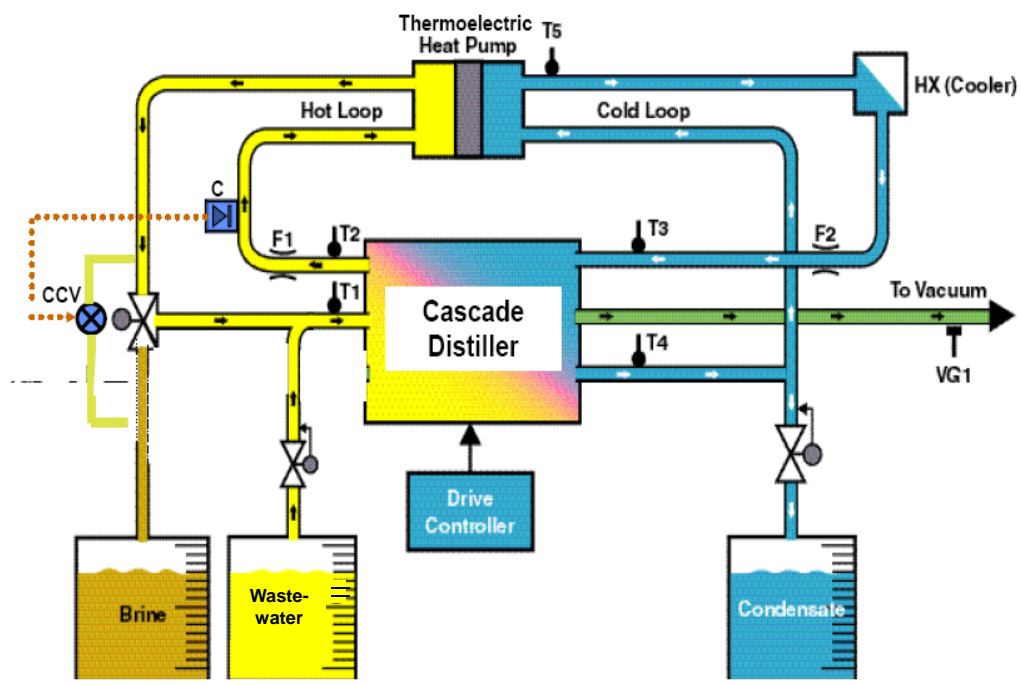

Figure 1. Simplified depiction of current CDS. compression heat pump assembly composed of three vapor compression cycles. In the paper, the CDS system level requirements are outlined, the flight-like designs of the two heat pumps are described in detail, and their performance predictions are provided. In addition, performance test results for the vapor compression heat pump are summarized. The heat pump mass, volume, and power trades are described and an enumeration of the advantages and disadvantages of each system is made.

\section{Cascade Distillation Subsystem Overview}

The Cascade Distillation Subsystem, shown in Fig. 1, consists of the cascade distiller, two recirculating fluid loops, a heat pump, a trim cooler, feed and product tanks, and a vacuum pump (not shown in the figure). The wastewater stream and condensate stream flow through the cascade distiller in a counterflow configuration. The distiller contains five interconnected chambers, each of which contains hot wastewater and cool condensate separated by a partition. In each chamber water and volatiles evaporate from the wastewater then condense on the condensate side of the partition. The pressure in the distiller is maintained below atmosphere by the vacuum pump. Pressures in the chambers are managed to create a negative pressure gradient from the hottest to the coldest chamber. The rotating chambers provide the motive force to transfer the condensate and wastewater from chamber to chamber and through the CDS loop.

Wastewater is introduced into the wastewater loop from a storage tank at a rate that is small compared to the fluid recirculation rate. The wastewater recirculation stream is heated by the heat pump to provide energy for evaporation. The evaporant condenses in the condensate recirculation loop, which is cooled by the heat pump. Condensate is removed from the system as it is generated. Concentrated wastewater brine is removed to maintain a constant fluid inventory in the system. The trim cooler removes excess heat from the condensate loop to maintain the system at the desired condition. One third of the condensate cooling is provided by the trim cooler.

The pre-prototype CDS uses a non-flight-like thermoelectric heat pump (TEHP) ${ }^{\ddagger}$. Two technologies were considered for the new flight-like heat pump, a series of mini vapor compression cycles and a redesigned TEHP using state-of-the-art thermoelectrics. The vapor compression version was brought forward because, with a power draw of $395 \mathrm{~W}$, the pre-prototype heat pump consumes over $60 \%$ of the CDS total power allotment. Implementing the vapor compression heat pump technology in the CDS would significantly reduce the CDS required power. In addition, the significantly higher COP of the vapor compression cycle would provide enough cooling that the low temperature trim cooler could be eliminated. Trim cooling would still be required, but it could be provided on the high temperature side, significantly reducing the spacecraft requirements.

Preliminary designs were developed for each option and their expected performances were predicted analytically. The analyses showed that both options were capable of meeting the CDS requirements. Therefore, both were pursued as possible replacements of the current CDS heat pump.

\footnotetext{
¥ Supplied by the Thermodistillation Co., Kyiv, Ukraine.
} 


\section{Heat Pump Descriptions}

\section{A. Thermoelectric Heat Pump}

The prototypic thermoelectric heat pump was designed to incorporate all of the key features of a flight unit. The fluid flow, heat transfer, and thermoelectric operation were all designed to be prototypic. In addition, the wetted materials were selected to be compatible with pretreated urine (a highly corrosive mixture of urine and acid), since this is the most corrosive possible wastewater mixture. The TEHP was fabricated from Inconel 625, which is one of the few metals compatible with pretreated urine. Metal-to-metal fittings and welded construction were used to avoid the presence of elastomers that could be attacked or a second metal (such as a brazing material) that would invite corrosion. There were two non-flight aspects of the TEHP. Readily available standard stainless steel tubing and fittings were used to meet the short desired lead time, plus it was not weight optimized. The prototype TEHP is designed so that all the stainless steel hardware can be replaced with Inconel 625 to upgrade the unit to be fully compatible with long term exposure to pretreated urine.

The TEHP was designed as a layered assembly of interwoven coldplates and thermoelectric module assemblies. The coldplates alternate between hot side and cold side flows so that each TEC is sandwiched between hot side and cold side coldplates. The TEHP was designed so that it could be disassembled to service the thermoelectric modules if needed.

The prototypic TEHP was designed to meet or exceed the thermal performance of the ground test TEHP while not exceeding the allowable pressure drop. The TEHP performance specifications are:

- No more than $9.8 \mathrm{kPa}$ pressure drop for each side at a flow rate of $90 \mathrm{~kg} / \mathrm{hr}$.

- $\geq 490 \mathrm{~W}$ of cooling with a cold side inlet temperature of $27.3^{\circ} \mathrm{C}$ (equivalent to an outlet temperature of $22.7^{\circ} \mathrm{C}$ at $\left.90 \mathrm{~kg} / \mathrm{hr}\right)$.

- $\geq 945 \mathrm{~W}$ of heating with a hot side inlet temperature of $36.9^{\circ} \mathrm{C}$ (equivalent to an outlet temperature of $46.1^{\circ} \mathrm{C}$ at $90 \mathrm{~kg} / \mathrm{hr}$ ).

Marlow RC12-6 thermoelectric modules were selected for the TEHP because of their good performance over the expected temperature and heat flux range. Stockwell TWS910-40TC thermally conductive elastomer was chosen as an interface material between the thermoelectric modules and the coldplates. This elastomer is a $1.02 \mathrm{~mm}$ 40 durometer sheet with a thermal conductivity of $4.98 \mathrm{~W} / \mathrm{m} \mathrm{K}$. The elastomer was purchased with a thermally conductive adhesive on one side to aid in assembly. The adhesive is $0.08 \mathrm{~mm}$ thick and has a thermal conductivity of $0.4 \mathrm{~W} / \mathrm{m} \mathrm{K}$.

The coldplates were designed to have flow channels only in line with the thermoelectric modules. The channel height was minimized to maximize the film coefficient. A channel height of $1.00 \mathrm{~mm}$ was selected as it was considered to be the lower limit of consistent machinability. The pressure vessel thickness is $1.50 \mathrm{~mm}$. The inlet and outlet manifolds are located along one edge of each coldplate and a plenum runs along the opposite edge. Thus the flow path is from the inlet manifold, across half of the coldplate, into the plenum, then back across the other coldplate half into the exit manifold.

An Excel spreadsheet was developed to optimize the number of thermoelectric modules, the number of coldplate layers, and the placement of the modules within each TEC layer. The spreadsheet included digitized and interpolated versions of the Marlowe-provided RC12-6 performance curves, the thermal resistance of the elastomer (assuming

Table 1: Analysis results for thermoelectric heat pump.

\begin{tabular}{ccccccc}
\hline $\begin{array}{c}\text { TEC } \\
\text { Count }\end{array}$ & $\begin{array}{c}\text { Amperage } \\
\text { per TEC }\end{array}$ & $\begin{array}{c}\text { Total } \\
\text { power, } \mathbf{W}\end{array}$ & $\mathbf{T}_{\text {hot,in }}\left({ }^{\circ} \mathbf{C}\right)$ & $\mathbf{T}_{\text {hot,out }}\left({ }^{\circ} \mathbf{C}\right)$ & $\mathbf{T}_{\text {cold,out }}\left({ }^{\circ} \mathbf{C}\right)$ & $\mathbf{T}_{\text {cold,in }}\left({ }^{\circ} \mathbf{C}\right)$ \\
\hline 60 & 1.668 & 465 & 36.9 & 46.1 & 27.4 & 22.7 \\
72 & 1.489 & 445 & 36.9 & 46.1 & 27.6 & 22.7 \\
84 & 1.357 & 431 & 36.9 & 46.1 & 27.8 & 22.7 \\
96 & 1.255 & 421 & 36.9 & 46.1 & 27.9 & 22.7 \\
108 & 1.175 & 415 & 36.9 & 46.1 & 27.9 & 22.7 \\
120 & 1.111 & 411 & 36.9 & 46.1 & 30.0 & 22.7 \\
\hline & & & & \\
& & & $36.9^{\circ} \mathrm{C}$ & $46.1^{\circ} \mathrm{C}$ & $27.3^{\circ} \mathrm{C}$ & $22.7^{\circ} \mathrm{C}$ \\
\hline
\end{tabular}

3

American Institute of Aeronautics and Astronautics 


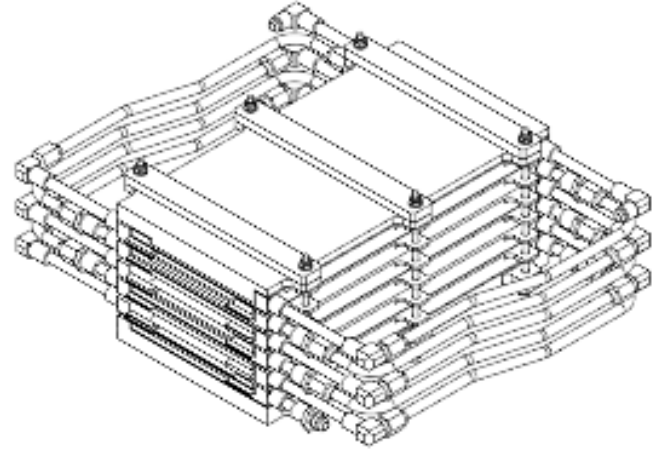

Figure 2. TEHP assembly

$10 \%$ compression), plus the thermal resistances of the adhesive, the coldplate wall, and the fluid film. The spreadsheet calculation began at one end of the counterflow heat exchanger and proceeded along the heat exchanger calculating the heat transfer and fluid temperature rise (or drop) caused by each thermoelectric module in

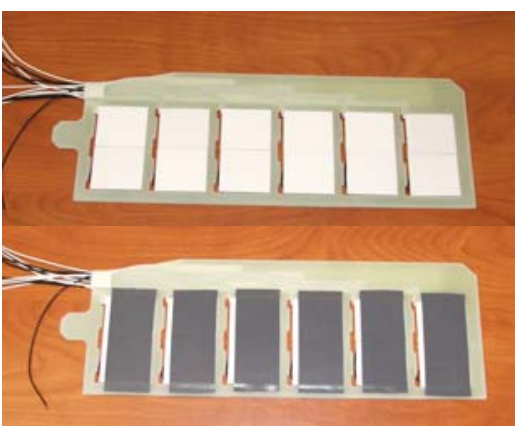

Figure 3. Thermoelectric module assembly

The temperatures at the cold end of the heat exchanger were used as inputs - the outlet temperature of the cold stream $\left(22.7^{\circ} \mathrm{C}\right)$ and the inlet temperature of the hot stream $\left(36.9^{\circ} \mathrm{C}\right)$. The flow rate in the model was set at $90 \mathrm{~kg} / \mathrm{hr}$. The number of thermoelectric modules was chosen in multiples of 12 . For each case the thermoelectric voltage was adjusted until the hot side outlet temperatures were consistent with the specification. That is, the hot side exit temperature matched its target of $46.1^{\circ} \mathrm{C}$ and the cold side inlet temperature exceeded its target of $27.3{ }^{\circ} \mathrm{C}$. Thus the hot side fluid heating met the specification and the cooling exceeded the specification. Analysis cases were performed for 60 to 120 thermoelectric modules. The results are summarized in Table 1.

The table shows that the total system power decreases as the number of thermoelectric modules increases. Of course, increasing the number of thermoelectric modules also increases the mass and volume of the TEHP. A preliminary selection of 96 thermoelectric modules was made, since this appeared to be near the optimum combination of TEHP size and power draw. However, the TEHP test article was designed to have a variable number of layers, allowing thermoelectric module counts up to 120 .

The thermoelectric heat pump assembly is shown in Fig. 2. The figure shows the interwoven layers of coldplates containing the hot and cold loops. Ten thermoelectric and 11 coldplate layers are shown as this is the maximum 120 thermoelectric module configuration. Thermoelectric and coldplate layers can be removed to test different configurations.

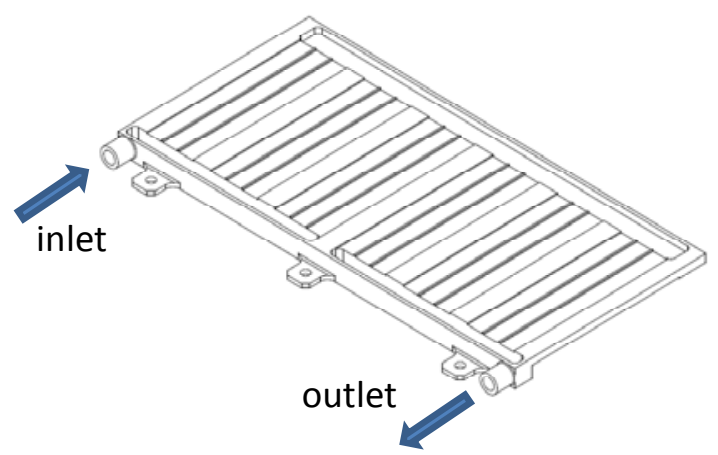

Figure 4. Coldplate with closeout plate removed.

Figure 3 shows, at top, six pairs of thermoelectric modules placed in the G10 glass epoxy laminate spacers that were used to positively locate them relative to the coldplate flow paths and, at bottom, the completed spacer assembly with the TWS910 elastomers mounted on the top and bottom of each pair of thermoelectric modules.

The fluid passages in a typical coldplate are shown in
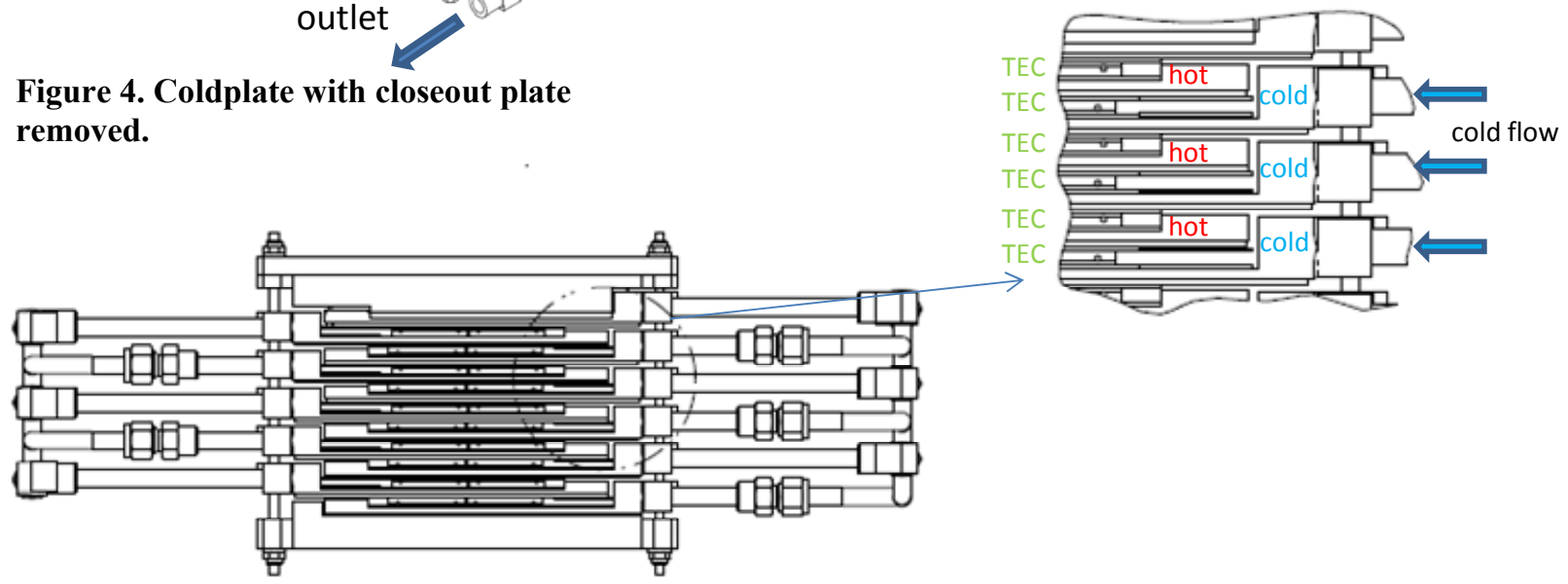

Figure 5. Heat exchanger side view and cross-section. 
Fig. 4. The figure shows the inlet and outlet manifolds, plus the turning plenum on the opposite side. Each coldplate contains six main passages each $1.02 \mathrm{~mm}$ high and $40.13 \mathrm{~mm}$ wide. This width matches the active width of the thermoelectric modules. Each main passage is subdivided into three passages by thin lands. The lands carry the elastomer compression load. The hot and cold side coldplates are identical.

The layup cross-section in Fig. 5 shows the alternating hot and cold layers separated by thermoelectric module assemblies. The design of the coldplates allows them to nestle when their orientation is alternated. The complete laid up assembly is sandwiched between G10 top and bottom plates and

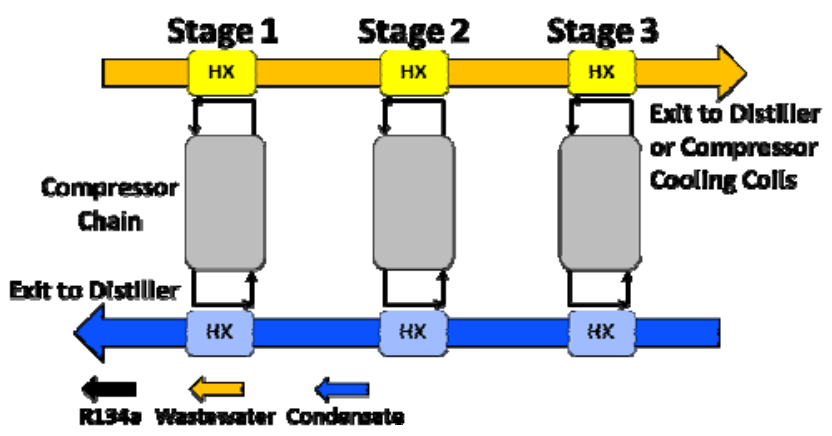

Figure 6. Simplified depiction of VCHP configuration.

stainless steel cross pieces and is compressed by the six $4.76 \mathrm{~mm}$ through bolts shown in Fig. 2. The through bolts, which index the coldplates and thermoelectric assemblies, are torqued to obtain a compressive pressure of $690 \mathrm{kPa}$ on the thermoelectric modules. This force compresses the elastomers to provide intimate contact between the TECs, elastomers, and coldplates.

Each coldplate is 0.17 by $0.35 \mathrm{~m}$. The assembled stack of 11 coldplates and $10 \mathrm{TEC}$ assemblies is $0.13 \mathrm{~m}$ tall. With the $9.5 \mathrm{~mm}$ OD tubing attached to connect the coldplates, the assembly width increases to $0.44 \mathrm{~m}$.

\section{B. Vapor Compression}

The proposed VCHP is a triplex combination of vapor compression cycles as shown in Fig. 6. Each stage contains an Embraco linear microcompressor and two counterflow heat exchangers serving as the cycle's evaporator and condenser. Wastewater and condensate flow through the heat exchangers where they are heated and cooled, respectively. Embraco compressors were selected because they are oil-free and can thus operate in microgravity\$. The compressors are small - about the size of a common soft drink can, weigh $1.4 \mathrm{~kg}$ each, and can be set to run at any capacity from $50 \%$ to $100 \%$.

One limitation of these compressors is that they cannot operate with a shell temperatures exceeding $80{ }^{\circ} \mathrm{C}$. This is not a problem in a laboratory environment. However, to satisfy spaceflight acoustics requirements the VCHP would be encapsulated in sound insulation, severely limiting the available cooling. One solution is to cool the compressor with sub $80{ }^{\circ} \mathrm{C}$ wastewater flowing out of the triplex heat pump. Heat added to the wastewater from the compressor would also promote further evaporation in the Cascade Distiller.

The vapor compression heat pump system was designed to meet the heat pump specifications and perform the

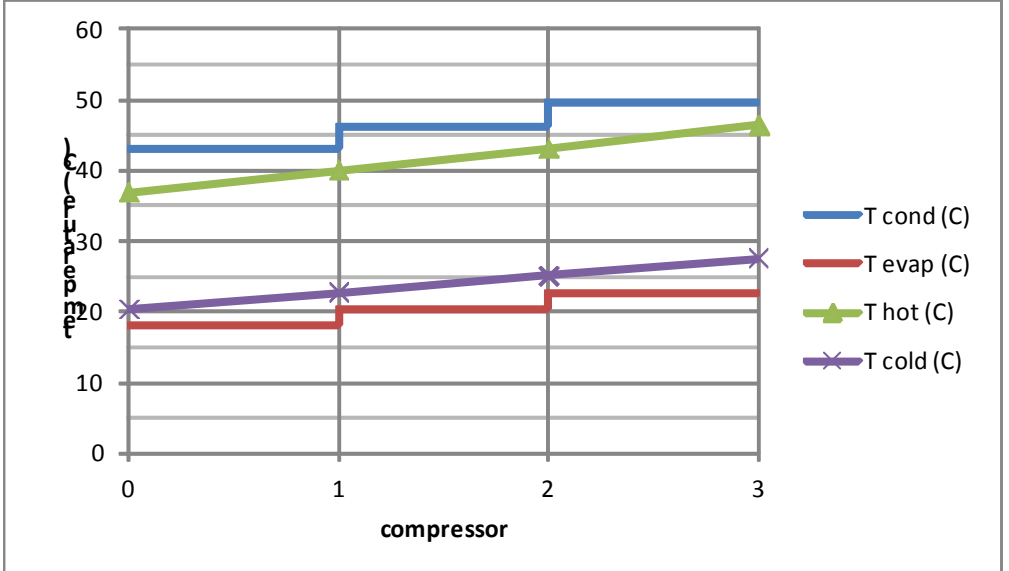

Figure 7. Vapor Compression Performance Predictions. Red and blue are predicted refrigerant temperatures for the vapor compression system. Green and purple are the predicted water temperatures. function of the trim cooler. The VCHP performance specifications are:

- No more than $9.8 \mathrm{kPa}$ pressure drop for each side at a flow rate of $90 \mathrm{~kg} / \mathrm{hr}$.

- $\geq 735 \mathrm{~W}$ of cooling with a cold side inlet temperature of $27.3{ }^{\circ} \mathrm{C}$ (equivalent to an outlet temperature of $20.4{ }^{\circ} \mathrm{C}$ at $90 \mathrm{~kg} / \mathrm{hr}$ ). This includes the ground test trim cooler function.

- $\geq 945 \mathrm{~W}$ of heating with a hot side inlet temperature of $36.9^{\circ} \mathrm{C}$ (equivalent to an outlet temperature of $46.1^{\circ} \mathrm{C}$ at $90 \mathrm{~kg} / \mathrm{hr}$ ).

\footnotetext{
$\S$ Prior to the present work, the compressors were tested to verify they could function in any orientation. However, the liquid configuration must be managed prior to startup to avoid slugging the compressor with liquid.
} 
The $100 \%$ capacity performance curves provided by the manufacturer were digitized and interpolated to allow calculation of the expected compressor performance at any selected hot side and cold side refrigerant temperatures. An Excel model was then developed to track the heating and cooling of the wastewater and condensate for three compressors in series. Heat exchanger efficiencies of 0.50 yielded the performance curves shown in Fig. 7. The figure shows the hot and cold side refrigerant temperatures of the three vapor compression cycles and the wastewater and condensate temperatures for the design water flow rates of $90 \mathrm{~kg} / \mathrm{hr}$. The triplex system meets the CDS VCHP heating and cooling requirements. It provides $1000 \mathrm{~W}$ of heating and $760 \mathrm{~W}$ of cooling with a predicted electrical power draw of $237 \mathrm{~W}$. The elimination of the trim cooler on the cold side of the CDS would allow trim cooling from the hot side to the ambient air - a significant advantage in overall system

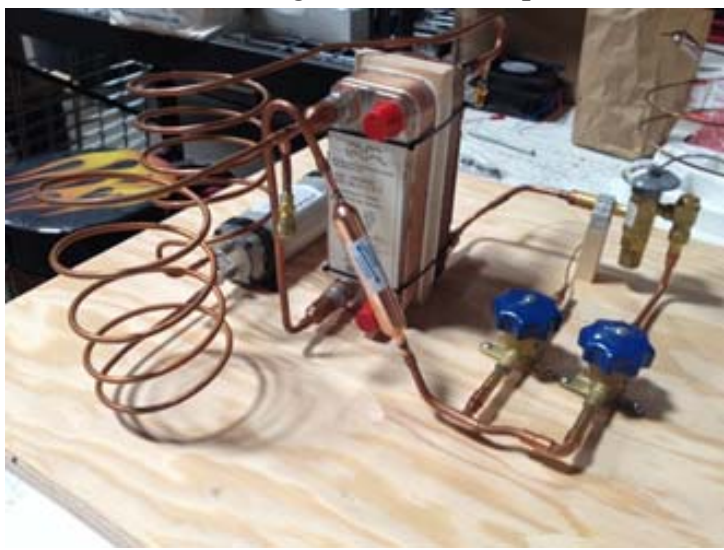

Figure 8. Single stage VCHP test article. design.

The triplex design of the VCHP provided an opportunity for segmented testing. Because each stage is mechanically identical yet separate, a single vapor compression assembly could act as any stage in the heat pump. To test the VCHP concept, each of the three heat pump cycles were sequentially mimicked to explore the overall performance of the three compressor system.

\section{VCHP Test Materials and Methods}

A two-part VCHP proof of concept test was conducted to verify the VCHP performance predictions. The first part verified the performance predictions discussed previously. The second part demonstrated that compressor cooling using the hot wastewater was feasible.

\section{A. Test Setup}

The heart of the test setup is a single VCHP, pictured in Fig. 8. The VCHP included the Embraco linear microcompressor, two CB14-12H Alpha Laval heat exchangers, associated plumbing and instrumentation. The VCHP was charged with R-134a. The compressor was powered by a 26 VDC $(3.1 \mathrm{~A})$ power supply. Its capacity was controlled with manufacturer supplied software. During testing, the entire heat pump loop was insulated other than the compressor was insulated.

A schematic of the test setup is shown in Fig. 9. Cold and hot tap water loops, constructed with $1 / 2$ " CPVC pipe, simulated the CDS's cold condensate and hot wastewater loops. Water flowed through each loop at the CDS's flow rate of $90 \mathrm{~kg} /$ hour. Flow through the cold loop was provided by a centrifugal pump and set with a manual needle valve. In the hot loop, flow was provided by a Thermocube chiller and adjusted by a manual needle valve. When the

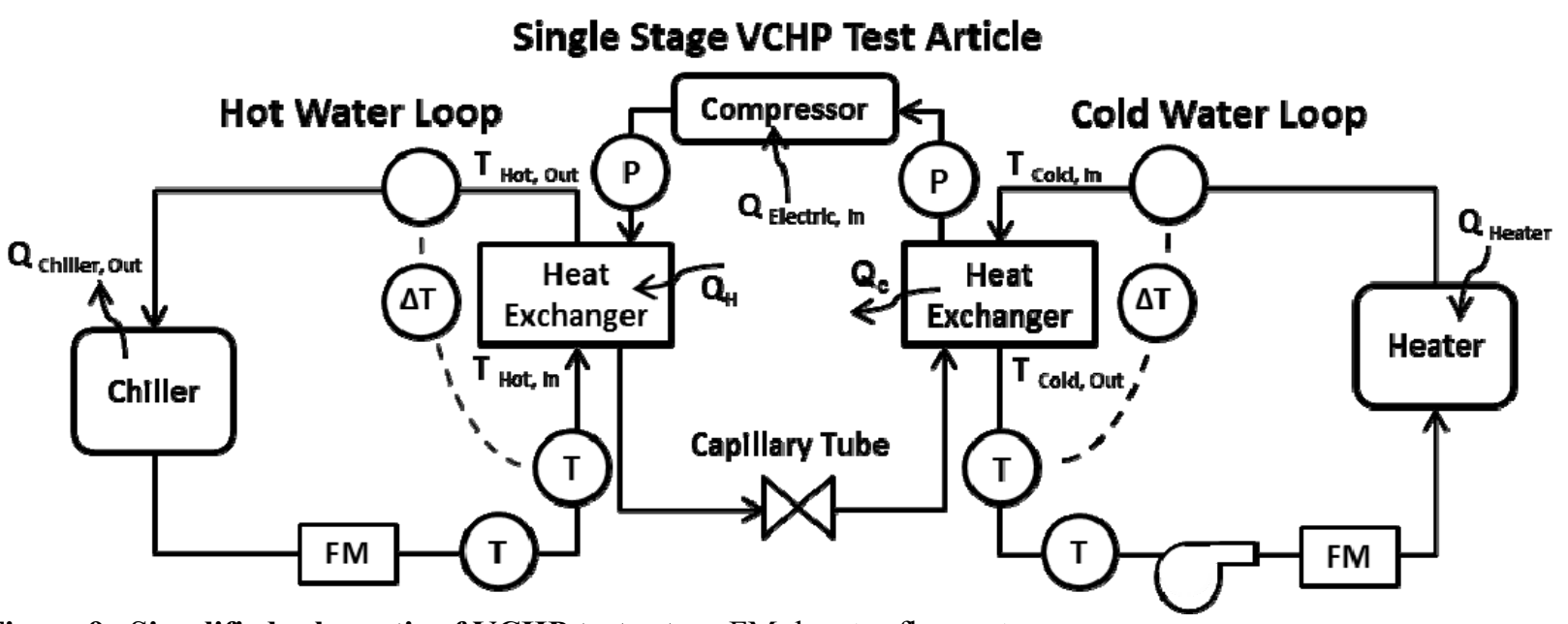

Figure 9. Simplified schematic of VCHP test setup. FM denotes flowmeter. 
VCHP was powered on, it transferred heat from the cold to the hot loop. A $3 \mathrm{~kW}$ heater in the cold loop was controlled via LabviewVI and the Thermocube chiller in the hot loop maintained its temperatures.

The test setup's data acquisition system (DAQ) consisted of Logic Beach's IL-80 and ILIM-7 data logging components and Hyperware Software. This system provided a total of 19 analog inputs with an advertised accuracy of $+/-0.03 \%$ of full scale VDC. Because only steady-state performance of the VCHP was desired, data was recorded once every three seconds. To capture the VCHP's steady-state power, the compressor's amperage draw was measured by an AAC S770 Series DC current transducer and the voltage supplied to the compressor was measured directly by the DAQ. The test article was equipped with WIKA General Purpose

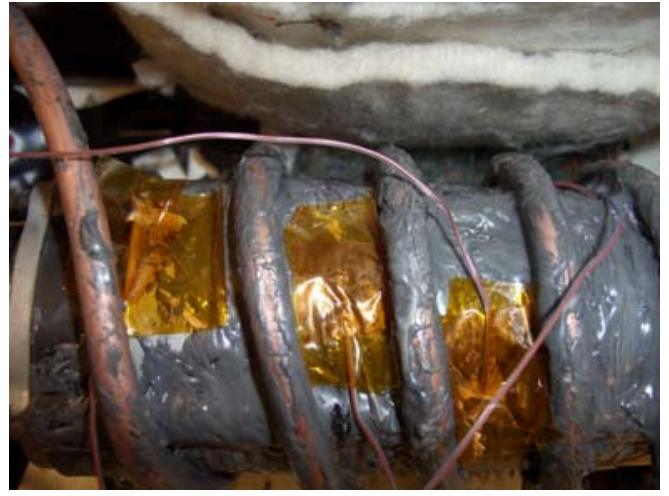

Figure 10. Compressor cooling coils. Type A-10 pressure transducers to capture evaporation and condensation pressures. Type $T$ immersion thermocouples measured the water temperatures entering the hot loop heat exchanger and exiting the cold loop heat exchanger. Temperature changes across each heat exchanger were found with two type $\mathrm{T}$ immersion thermocouples wired so one acted as the reference junction.

Table 2 lists the test instrumentation, range, and accuracy. Other than the temperature difference measurements, the listed accuracies are from manufacturer specifications. The end-to-end accuracy of the thermocouples was checked by placing them in a well stirred ice bath and reading their measurements via the data acquisition system. The measurements all agreed within the manufacturer's stated accuracy of $\pm \leq 1.4{ }^{\circ} \mathrm{C}$. The accuracy of the temperature difference measurements was measured in the same well stirred bath and was found to be $\pm \leq 0.5{ }^{\circ} \mathrm{C}$.

The test setup was modified slightly for the second portion of the test. A portion of the hot water leaving the heat exchanger was directed through copper coils wrapped around the compressor before returning to the chiller. JB weld was used to connect the coils and the compressor. Five type T stick on thermocouples were attached to the compressor in between the copper coils where the compressor would be warmest, and the compressor was wrapped in insulation

\section{B. Test Operation}

The same procedure was used in each test point to allow a full scale VCHP's performance to be mapped using

Table 2: VCHP test instrumentation.

\begin{tabular}{|c|c|c|}
\hline Instrument & Measurement & Accuracy/ Range \\
\hline $\begin{array}{l}\text { WIKA General Purpose Pressure } \\
\text { Transmitters Type A-10 }\end{array}$ & Refrigerant pressures in VCHP & $\begin{array}{c} \pm \leq 17 \mathrm{kPa} / \\
0 \text { to } 1725 \mathrm{kPa}\end{array}$ \\
\hline $\begin{array}{c}\text { Logic Beach IL-80 and ILIM-7 } \\
\text { data logger }\end{array}$ & Compressor power source voltage & $\begin{array}{l} \pm 0.9 \mathrm{VDC} / \\
0 \text { to } 30 \mathrm{VDC}\end{array}$ \\
\hline $\begin{array}{c}\text { AAC Series S770 DC Current } \\
\text { Transducer }\end{array}$ & Compressor power source amperage & $\begin{array}{l} \pm 0.1 \mathrm{~A} / \\
0 \text { to } 10 \mathrm{~A}\end{array}$ \\
\hline $\begin{array}{c}\text { Micro Motion R025S Series } \\
\text { Coriolis Flowmeter \& } 1500 \text { Series } \\
\text { Flow Transmitter }\end{array}$ & Water loop mass flow rates & $\begin{array}{l} \pm 0.5 \% \text { of flow } / \\
0 \text { to } 2720 \mathrm{~kg} / \mathrm{hr}\end{array}$ \\
\hline Type T immersion thermocouple & $\begin{array}{l}\text { Cold loop's heat exchanger outlet temperature } \\
\text { Hot loop's heat exchanger inlet temperature }\end{array}$ & $\pm \leq 1.4^{\circ} \mathrm{C}$ \\
\hline $\begin{array}{l}\text { Pair of Type T immersion } \\
\text { thermocouples }\end{array}$ & $\begin{array}{l}\text { Temperature difference across heat exchangers in } \\
\text { water loops }\end{array}$ & $\pm \leq 0.5^{\circ} \mathrm{C}$ \\
\hline Type T stick on thermocouple & $\begin{array}{c}\text { Hot loop's heat exchanger outlet temperature } \\
\text { Compressor shell temperatures } \\
\text { Outlet of copper coils wrapped around the } \\
\text { compressor } \\
\text { Ambient temperature }\end{array}$ & $\pm \leq 1.4^{\circ} \mathrm{C}$ \\
\hline
\end{tabular}


the single stage VCHP test article. Each test point consisted of three runs simulating, in turn, each stage of the triplex VCHP. To begin a test, the VCHP and water pumps were turned on. The VCHP was then adjusted to the desired capacity and the heater and chiller were adjusted to yield the desired lowest temperatures of the cold and hot loops (the cold loop's heat exchanger outlet temperature and the hot loop's heat exchanger inlet temperature) at steady-state. The resulting high temperatures (the cold loop's heat exchanger inlet temperature and the hot loop's heat exchanger outlet temperature) were then used as the lowest temperatures for the second steady-state run. Likewise, the second run's resulting high temperatures of the cold and hot loops were set as the lowest temperatures for the third run. No more than $\pm 0.1^{\circ} \mathrm{C}$ difference was allowed when obtaining the desired conditions.

During each test point the pressure, temperature, voltage, and amperage measurements listed in Table 2 were taken. The compressor shell temperatures were only recorded during part two of the test, but the compressor was continuously monitored to insure that it did not overheat. Additionally in the second portion of the test, the temperature at the outlet of the copper coils around the compressor was also periodically measured via a stick on thermocouple and a thermocouple reader. The bucket and stopwatch method was used to measure flow through the copper coils.

The list of completed test points is contained in Table 3. The nominal CDS operating condition test point for the VCHP was performed four times, the last time with the liquid cooled compressor. In addition, test points with different temperature (and cooling and heating) targets and different compressor capacities were performed to explore the VCHP capabilities.

\section{Data Analysis}

All calculations for characterizing the steady-state performance of the triplex VCHP are based on average parameters from 15 minutes of steady-state operation. The steady-state power draw of each stage was found by multiplying the current draw and the supplied voltage. The total power of the triplex VCHP was taken as the sum of the average power draw from each stage. To determine the heat transferred by the VCHP, an energy balance was performed on the hot and cold water at the heat exchangers. For part two's test point, the heat transfer from the compressor to the hot loop was not considered a contributor to the VCHP's performance. VCHP evaporation and condensation temperatures were found using measured pressures and R134a ${ }^{2}$ saturation curves. Heat exchanger effectiveness and COP were calculated using standard methods.

From part two of the test, the heat transferred from the hot water loop to the copper coils was calculated using two methods. Direct measurement of the inlet and outlet water temperatures from the stick-on thermocouples yielded a temperature difference of less than $0.5^{\circ} \mathrm{C}$, which is smaller than the sensor accuracy of $\pm 1.5^{\circ} \mathrm{C}$. So, the heat exiting the compressor was bounded as the total heat lost from the test article. Averages were taken of $\mathrm{Q}_{\text {cooling, }}$ $\mathrm{Q}_{\text {heating, }}$, and power into the compressor for test runs that mimicked the third stage of the VCHP at CDS nominal operating conditions. An energy balance using these averages showed that the heat lost by the compressor shell could not have exceeded $39 \mathrm{~W}$. From the bucket and stopwatch method, $65 \mathrm{~kg} /$ hour of hot water was found to flow through the copper coils. If $39 \mathrm{~W}$ was the cooling water heat load, the water's temperature would rise $0.51{ }^{\circ} \mathrm{C}$, which is consistent with the thermocouple measurements. Therefore, less than $39 \mathrm{~W}$ is estimated to have entered the hot water from the compressor shell. This minor heat load can easily be absorbed into the hot loop.

\section{Table 3: List of VCHP test points.}

\begin{tabular}{cr}
\hline Test Points & Condition \\
\hline $\begin{array}{c}\text { TP1, TP4, TP6, } \\
\text { TPC (Part two's test point) }\end{array}$ & $\begin{array}{r}\text { Nominal CDS operating conditions where }-100 \% \text { compressor capacity } \\
\text { Both hot side inlet temperature and cold side outlet temperature at } 3{ }^{\circ} \mathrm{C} \text { greater } \\
\text { than nominal CDS operating conditions }-75 \% \text { compressor capacity }\end{array}$ \\
TP5 & $\begin{array}{r}\text { Hot side inlet temperature at } 2.5^{\circ} \mathrm{C} \text { greater than nominal CDS operating } \\
\text { conditions and cold side outlet temperature at } 4.5^{\circ} \mathrm{C} \text { greater than nominal CDS } \\
\text { operating conditions }-100 \% \text { compressor capacity }\end{array}$ \\
TP2 & $\begin{array}{r}\text { Hot side inlet temperature at } 4.5^{\circ} \mathrm{C} \text { greater than nominal CDS operating } \\
\text { conditions and cold side outlet temperature at } 4.5^{\circ} \mathrm{C} \text { less than nominal CDS } \\
\text { operating conditions }-100 \% \text { compressor capacity }\end{array}$ \\
TP3 &
\end{tabular}




\section{VCHP Test Results}

\section{A. Compressor Performance Relative to Manufacturer's Data}

The performance of the test article's microcompressor was compared with the manufacturer's performance curves that were the basis of the VCHP's performance predictions. Figures 11 and 12 compare the compressor's steady-state cooling and COP at $100 \%$ capacity against the stated values. For $100 \%$ agreement, the plotted points should all be enveloped by the two lines of the manufacturer's predictions. The test results are generally consistent with the manufacturer's curves.

Three data points fell below Embraco's curves in both Figures 11 and 12. These points are TP3. TP3 was run sequentially with the other tests and the test setup was neither broken into nor altered between TP3 and the previous test point. During TP3 the compressor's current draw fell within the range of the other test runs at $100 \%$ capacity indicating the decreased cooling was not due to decreased compressor capacity. The only distinguishing factor between TP3 and the other test points is that it had the highest temperature difference across the heat pump, $9{ }^{\circ} \mathrm{C}$ greater than the test points at nominal conditions and $16^{\circ} \mathrm{C}$ more than TP2. TP3's anomalous compressor performance remains unexplainable. However, we still have confidence in the VCHP predictions because the vast majority of the test points yielded data in accordance with manufacturer's curves.

\section{B. Triplex VCHP Capability}

At nominal CDS conditions, the triplex VCHP met the CDS's cooling requirement but fell slightly short of meeting the heating requirement. Figure 13 presents temperature data for each simulated stage of the VCHP against predicted temperatures for the VCHP's design point at nominal CDS operations. The Excel model predicted that the VCHP would successfully heat $90 \mathrm{l} / \mathrm{hr}$ of wastewater from $36.9{ }^{\circ} \mathrm{C}$ to $46.1{ }^{\circ} \mathrm{C}$ while cooling the same amount of condensate from $27.3{ }^{\circ} \mathrm{C}$ to $20.4{ }^{\circ} \mathrm{C}$. The test data showed that the VCHP provided on average a $7.4{ }^{\circ} \mathrm{C}$ temperature drop in the cold loop, which exceeds the CDS's cooling requirement when no trim cooler is present. However, from Fig. 13 it is evident that about $10 \%$ less heat is transferred to the hot side than required. The disparity is caused by the fact that the evaporator's measured heat exchanger effectiveness was only $35 \%-$ considerably less than the $50 \%$ effectiveness assumed by the analysis. The condenser's measured heat exchanger effectiveness was $86 \%$, consistent with the $50 \%$ assumed in the model.

Improving the evaporator heat exchanger effectiveness would be easily accomplished. The test heat exchanger was an off the shelf unit chosen for availability and price. Purpose built heat exchangers can meet the $50 \%$ effectiveness used in the sizing analysis and can easily be designed for higher effectiveness to improve the VCHP

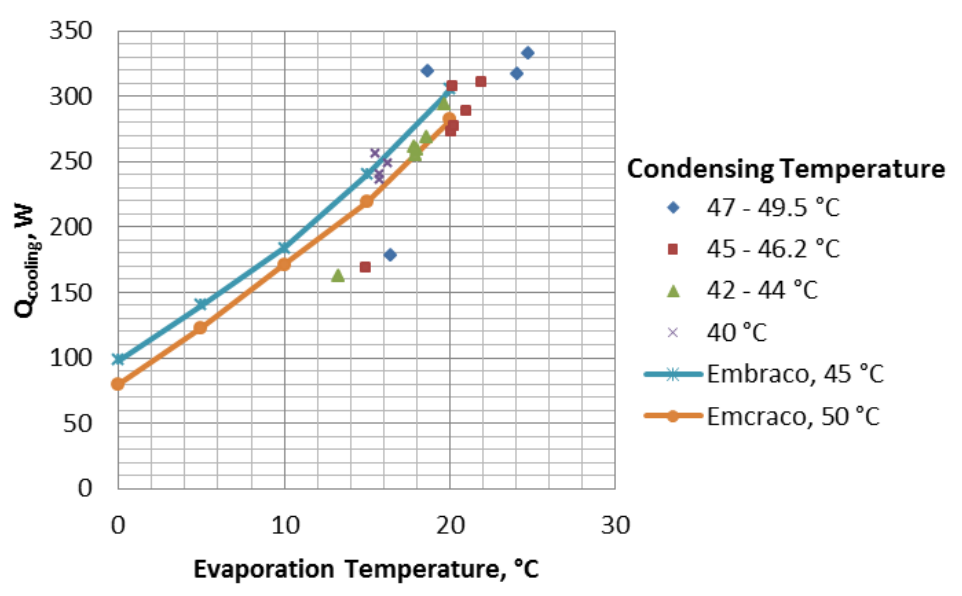

Figure 11. 100\% compressor capacity cooling. Test data plus manufacturer's performance curves.

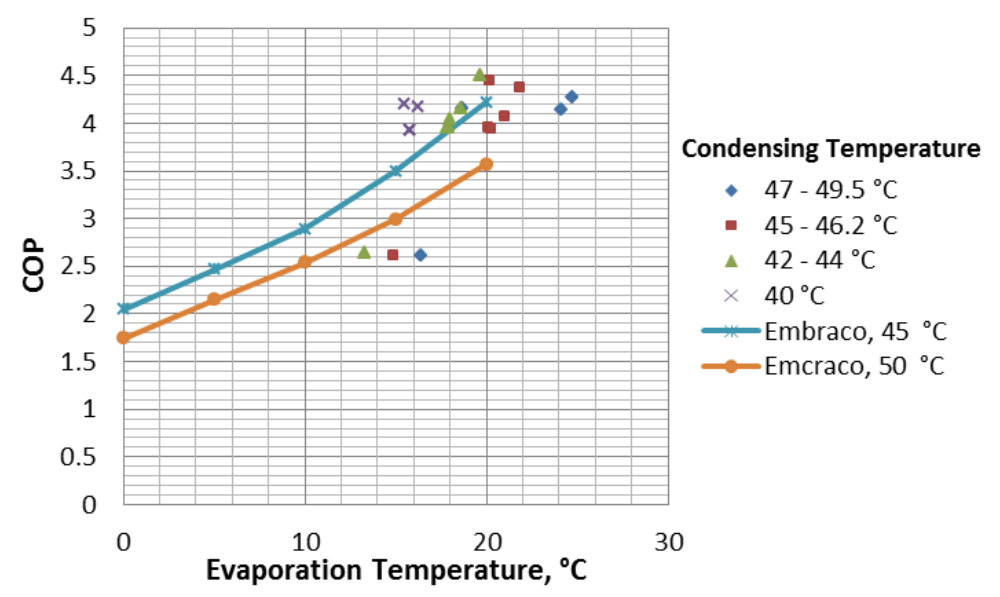

Figure 12. $100 \%$ compressor capacity COP. Test data plus manufacturer's performance curves. 
performance further. As a bonus, additional heat flow to the hot loop can be generated by adopting the compressor cooling scheme described above.

The triplex VCHP would significantly reduce the CDS's power consumption. Table 4 displays compressor power draw as well as the amount of heating and cooling achieved at steady-state nominal CDS operating conditions. The total steadystate power consumption of the triplex VCHP was $195 \mathrm{~W}$, which was less than its predicted $237 \mathrm{~W}$ consumption, and much less than the $395 \mathrm{~W}$ power draw of the pre-prototype CDS TEHP.

\section{Ability to Cool the Compressor Shell}

The testing demonstrated that the VCHP compressors can be successfully cooled using the hot wastewater flow. Figure 14 displays the compressor shell temperature for the third stage test using compressor cooling. Here, the average water temperature entering the coils was $45.1^{\circ} \mathrm{C}$. The compressor's shell temperature did not exceed $60^{\circ} \mathrm{C}$, well below the $80^{\circ} \mathrm{C}$ limit. The negligible water temperature rise measured in the test indicates that a low fraction of the total flow can be sent to the coils (well below the $73 \%$ of the total flow that was sent to the coils in the test) while still maintaining adequate compressor cooling.

\section{Improvements}

\section{A. VCHP Improvements}

Improved Heat Exchanger Design. Effective, light, and small heat exchangers are required for the VCHP to become a component of the CDS design. A preliminary design of an improved, compact heat exchanger was developed to demonstrate the feasibility of using the VCHP. Each of the two new VCHP heat exchangers would be built from three $0.0625 \mathrm{~m}$ tall by $0.0625 \mathrm{~m}$ wide by $0.0762 \mathrm{~m}$ long blocks of Inconel 625 . The three crossflow heat exchangers that make up a single unit would be assembled end-to-end as shown in Fig. 15 to minimize plumbing and to conserve volume. Each of the three heat exchangers would contain interwoven rectangular passages carrying either condensate or wastewater and R134a. The exchanger's height and width was chosen to accommodate standard 2" Inconel 625 tubing caps would be used as inlet and exit plena. The passages would be machined with wire EDM methods.

Both passage height and the number of passages were varied in an Excel spreadsheet that calculated the resulting heat exchanger effectiveness and pressure drop for water through the three heat exchangers in series. An equal number of water or wastewater and R-134a passages of identical heights was assumed. The passages were treated like infinite parallel plates for heat transfer and pressure drop because their height to width ratio was less than 0.1. A $1.5 \mathrm{~mm}$ walls separated the passages. Changing the number of passages changed the passage height. The spreadsheet calculated the heat exchanger UA and pressure drop. The results of the analysis are shown in Table 5. The table shows that an effectiveness near unity can be achieved while maintaining the pressure drop below the $9.8 \mathrm{kPa}$ limit 


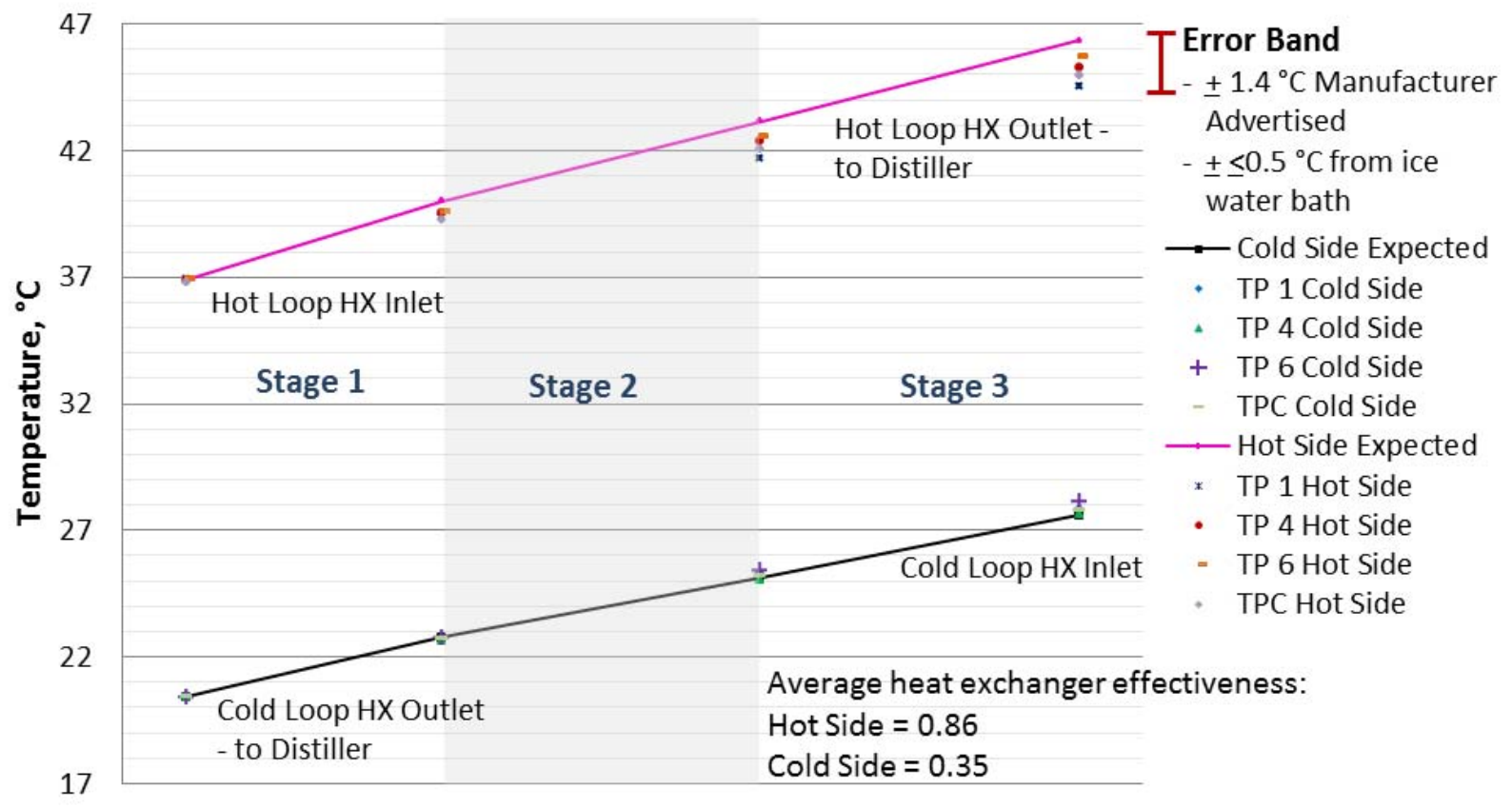

Figure 13. Test temperatures at CDS nominal operating conditions compared to analysis' predicted values, assuming a heat exchanger effectiveness of $50 \%$.

Table 4: VCHP performance. Nominal CDS operating conditions and $100 \%$ compressor capacity.

\begin{tabular}{crrr}
\hline Test Run & $\mathbf{Q}_{\text {cooling, }} \mathbf{W}$ & $\mathbf{Q}_{\text {heating }}, \mathbf{W}$ & \multicolumn{2}{c}{ Total Power Into Compressor, W } \\
\hline Simulating Stage 1 of VCHP & & \\
1.1 & 234.0 & 269.7 & 61.2 \\
4.1 & 235.8 & 278.6 & 60.1 \\
6.1 & 248.6 & 281.5 & 59.7 \\
C 1.1 & 238.4 & 256.5 & 61.0 \\
\hline Simulating Stage 2 of VCHP & & \\
1.2 & 259.4 & 285.0 & 64.1 \\
4.2 & 255.5 & 292.1 & 64.3 \\
6.2 & 269.2 & 305.7 & 64.8 \\
C 1.2 & 261.8 & 285.3 & 66.23 \\
\hline Simulating Stage 3 of VCHP & & 69.0 \\
1.3 & 273.3 & 295.4 & 69.1 \\
4.3 & 307.7 & 271.4 & 70.9 \\
6.3 & 289.0 & 329.1 & 70.4 \\
C 1.3 & 277.3 & 303.3 & \\
\hline Total of all Stages & & & $\mathbf{1 9 4 . 3}$ \\
1 & $\mathbf{7 6 6 . 7}$ & $\mathbf{8 5 0 . 1}$ & $\mathbf{1 9 3 . 5}$ \\
$\mathbf{4}$ & $\mathbf{7 9 9 . 0}$ & $\mathbf{8 4 2 . 1}$ & $\mathbf{1 9 5 . 4}$ \\
$\mathbf{6}$ & $\mathbf{8 0 6 . 8}$ & $\mathbf{9 1 6 . 3}$ & $\mathbf{1 9 4 . 3}$ \\
C 1 & $\mathbf{7 6 6 . 7}$ & $\mathbf{8 5 0 . 1}$ & \\
& & & \\
\hline
\end{tabular}


Table 5: Analysis results for improved heat exchanger design.

\begin{tabular}{ccccc}
\hline $\begin{array}{c}\text { Number of Water } \\
\text { Passages }\end{array}$ & $\begin{array}{c}\text { Passage } \\
\text { Height, } \mathbf{~ m m}\end{array}$ & $\mathbf{\Delta} \mathbf{P}_{\text {water, }}(\mathbf{k P a})$ & $\boldsymbol{\varepsilon}$ & $\begin{array}{c}\boldsymbol{\varepsilon} \text { Accounting for } \\
\text { Passage Height Tolerance }\end{array}$ \\
\hline 10 & 0.79 & 0.36 & 0.96 & 0.92 \\
11 & 0.58 & 0.81 & 0.99 & 0.95 \\
12 & 0.41 & 2.17 & 1.00 & 0.96 \\
13 & 0.26 & 7.77 & 1.00 & 0.97 \\
\hline
\end{tabular}

The second spreadsheet was built to investigate the effect of passage height tolerances on heat exchanger performance. Companies with EDM capability have claimed the ability to hold tolerances as small as $0.0025 \mathrm{~mm}$. Tolerance was included by treating the heat exchanger series as two parallel exchangers, each with half the total of passages. One exchanger's passage height was increased by $0.0050 \mathrm{~mm}$; the other's passage height was decreased by $0.0050 \mathrm{~mm}$. Refrigerant at $18.1{ }^{\circ} \mathrm{C}$, the average nominal CDS test refrigerant temperature, and $27.84{ }^{\circ} \mathrm{C}$ water, the average triplex VCHP cold water inlet temperature at nominal CDS conditions, were assumed to enter the separate exchangers. The flows were adjusted between the two heat exchangers until their pressure drops were equal. The outlet water temperatures of each half were then calculated. The mixed outlet water temperatures were used to find the overall effectiveness of the heat exchanger.

The results of the tolerance investigation are shown in Table 5. A $0.58 \mathrm{~mm}$ duct size was selected for the final design because this height produced a reasonably small pressure drop and maintained an effectiveness above $94 \%$, even with the effects of manufacturing tolerance included.

Acoustic Improvements. The VCHP compressor was found to be quite noisy during tests. The single stage VCHP sound level was measured as $62.4 \mathrm{dBA}$. Based on allowable noise levels on the International Space Station, a single VCHP stage would be limited to no more than one hour of operation daily. Since the VCHP has three compressors and would operate for multiple hours each day, noise abatement was pursued.

A preliminary assessment of encapsulating the VCHP with acoustic absorption and barrier materials has been made. It was found that any material in contact with the compressor or the R134a lines increased sound emissions, rather than dampened them. The compressor's low frequency, high amplitude vibrations excite anything in direct contact. Adding material also increased the system's surface area and consequently acts as an acoustic radiator. Significant noise reduction was achieved by encapsulating the test article with $0.0508 \mathrm{~m}$ thick Thinsulate and fiberglass reinforced $1.22 \mathrm{~kg} / \mathrm{m}^{2}$ density Bisco HT-200. The materials were prevented from contacting the compressor or the R134a lines by a large box frame. This encapsulation method decreased the article's sound levels to $50.2 \mathrm{dBA}$, showing that the VCHP's noise levels can be substantially reduced.

Other options for noise reduction were tried including trying different compressor mounts and replacing the copper refrigerant lines with flexible refrigeration lines. None of these attempts significantly lessened the test article noise. Extremely soft compressor mounting methods, such as suspending the compressor, in air were the most affective but would be very challenging to implement for flight. However, the flexible lines significantly decreased both noise and vibration within the rest of the structure. The challenge with mitigating the VCHP's sound will continue to be addressed in future work.

\section{B. TEHX Improvements}

No attempt was made to optimize the mass of the TEHP because it was designed to demonstrate the design concept, not as a flight unit. For a flight unit, a number of weight-optimizing changes could be incorporated:

- Elimination of the mechanical fittings in favor of all welded construction.

- Reduction of the manifold wall thickness.

- Mass optimization G10 top and bottom pieces and stainless steel cross pieces.

With these changes, the mass of the TEHP can be reduced.

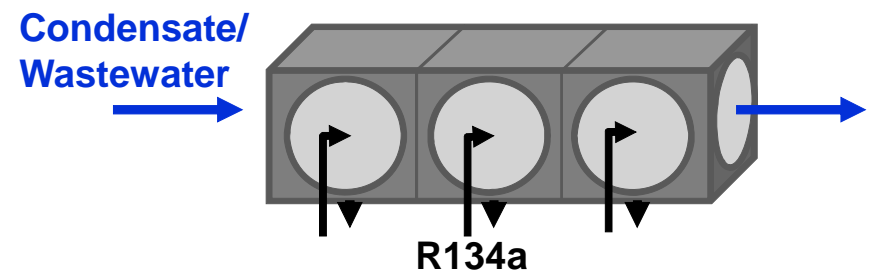

Figure 15. Simplified representation of improved VCHP heat exchanger design.

12

American Institute of Aeronautics and Astronautics 


\section{Performance Comparison and Recommendation LRE EKU}

The performance of the 96 TEC TEHX and the triplex vapor compression system are compared to the specifications in Table 5. The TEHP and triplex vapor compression heat pump both meet their respective performance requirements.

Table 5. Heat Pump Performance Comparison

\begin{tabular}{|l|c|c|c|}
\hline & specification & 96 TEC TEHP & $\begin{array}{c}\text { Triplex vapor compression } \\
\text { heat pump }\end{array}$ \\
\hline Qheat with $36.9^{\circ} \mathrm{C}$ inlet & 945 & 945 & 1000 \\
\hline$Q_{\text {cool }}$ with $27.3^{\circ} \mathrm{C}$ inlet & $\begin{array}{c}490 \mathrm{w} / \text { trim cooler } \\
735 \mathrm{w} / \mathrm{o} \text { trim cooler }\end{array}$ & 554 & 760 \\
\hline Electrical power $(\mathrm{W})$ & 600 & 421 & 237 \\
\hline Mass $(\mathrm{kg})$ & & 32 & 18 \\
\hline Volume $\left(\mathrm{m}^{3}\right)$ & & 0.02 & 0.005 \\
\hline
\end{tabular}

The TEHP and the triplex vapor compression heat advantages and disadvantages are summarized in Table 6. Both options are technically feasible but have issues. All the known issues can be dealt with in future work.

Table 6. Advantages and disadvantages of heat pump options.

\begin{tabular}{|c|c|c|}
\hline & TEHP & Triplex VCHP \\
\hline Advantages & Quiet & Lower power \\
& $\begin{array}{c}\text { No moving parts } \\
\text { High reliability }\end{array}$ & Eliminates trim cooler on cold loop \\
\hline Disadvantages & Heavy & Acoustics issues \\
& High power & 0 -g fluid management issues on startup \\
\hline
\end{tabular}

\section{Conclusions}

An analysis, design, and test program was performed to assess two options for the Cascade Distillation Subsystem heat pump heat exchanger:

- a flight-like thermoelectric heat pump

- a triplex vapor compression heat pump.

The study showed that both technologies meet the CDS requirements, but that both have issues that must be investigated further prior to the selection of a final design.

\section{References}

${ }^{1}$ Callahan, M. R., Patel, V., and Pickering, K. D., "Cascade Distillation Subsystem Development: Early Results From the Exploration Life Support Distillation Technology Comparison Test" 40th International Conference on Environmental Systems, Barcelona, Spain, July 11-15, 2010.

${ }^{2}$ REFPROP Reference Fluid Thermodynamic and Transport Properties, NIST Standard Reference Database 43, Version 7.1, National Institute of Standards and Technology, Gaithersburg, MD, 2010. 